\title{
Galvanic chloride extraction by an embedded zinc anode: Ion distribution mapped by laser induced breakdown spectroscopy (LIBS)
}

\author{
W. Schwarz ${ }^{1)}$, Gerd Wilsch ${ }^{2)}$, A. Pichlhöfer ${ }^{1)}$, G. Ebell ${ }^{2)}$, T. Völker ${ }^{2}$ \\ ${ }^{1}$ CAS Composite Anode Systems GmbH, Vienna, Austria \\ ${ }^{2} \mathrm{BAM}$ - Bundesanstalt für Materialforschung und -prüfung, Berlin, Germany
}

\begin{abstract}
An important aspect with regard to the service life of zinc based galvanic anodes and the durability of the corrosion protection of steel in concrete is the "galvanic chloride extraction". Chloride ions move in the electric field generated by the current, flowing between the galvanic anode and the cathodic steel. Migration leads to an accumulation of anions, e.g. chloride ions, at the anode and depletion of chlorides near the steel rebar surface. The ion migration was studied on steel reinforced concrete specimens admixed with $3 \mathrm{wt} . \%$ chloride/wt. cement and galvanically protected by a surface applied embedded zinc anode (EZA). The zinc anode was embedded and glued to the concrete surface by a geo-polymer based chloride free binder. The EZA was operated over a period of 1 year and the ion distribution between anode (EZA) and cathode (steel reinforcement) was studied by laser induced breakdown spectroscopy (LIBS) after 5 months, 7 months and 12 months. The results show that chloride ions efficiently migrate in the direction of the zinc-anode and accumulate there. Chloride distribution in the EZA correlates with the distribution of zinc ions generated by the anodic dissolution of the zinc anode in the binder matrix. The microstructure of the binder matrix and its interface to the zinc-anode are studied by REM/EDX - preliminary results will be reported.
\end{abstract}

\section{Introduction}

Galvanic corrosion protection of steel in concrete is based on the formation of a galvanic element when a metal which is less noble than cast iron steel, in direct contact with the concrete overlay, is electrically connected to the steel rebars. The reinforcing steel is protected from corrosion as long as sufficient galvanic current flows between the galvanic anode and the steel reinforcement. Most commonly, zinc is used as the sacrificial anode material. The galvanic element formed corresponds to a conventional zinc/air battery that is becoming popular again as an alternative source of energy.

Galvanic corrosion protection was first employed to protect a bridge deck in Illinois in 1977 within the cooperative highway research program, with mixed results [1]. A problem with the initially applied sacrificial anodes was that their protection current decreases with time, and they eventually become passive, so most systems have a relatively short useful life [2].

In the 1990's, sacrificial anode systems based on sprayed zinc anodes, zinc foil glued to the concrete surface (zinc hydrogel system) and zinc mesh pile jackets around bridge columns filled with sea water were starting to be evaluated and used for the protection of bridge structures [2-5].
The efficiency of galvanic corrosion protection depends on the lasting activity of the zinc anode. Deposition and agglomeration of the anodic products like zinc hydroxide and zinc hydroxychlorides or contact with calcium hydroxide in the pore solution may passivate the zinc anode surface. The service time of the zinc anode may be limited by self-corrosion which increases with the activation of the zinc anode and may reach up to $70 \%$ of the zinc consumed during operation.

A galvanic zinc anode system composed of a zinc mesh embedded into a proprietary mortar that solidifies into a solid electrolyte, installed on various civil structures (bridges, marine harbour piles, parking decks, tunnel entrances) protects the steel reinforcement reliably and efficiently from corrosion for up to 11 years [6]. The solid electrolyte of the embedded zinc anode system (EZA) is based on a tecto-alumosilicate-binder (TAS) containing additives that prevent passivation of the zinc anode, assure high and durable galvanic activity of the zinc anode and high and durable adhesion towards the concrete overlay.

Previous studies of concrete overlay samples drawn from field installations indicated chloride migration and chloride fixation near the zinc anode [7], however verification and quantification on samples drawn from field installations proved to be difficult as the original chloride distribution in the concrete and the embedding mortar are difficult to evaluate. 
Migration of chlorides in concrete in an applied electric field is well established and employed e.g. for rapid determination of diffusion constants in concrete [8-10]. The electric field generated by the galvanic current, is estimated to be in the range of $300-600 \mathrm{mV}$, estimated from the open-circuit potential between zinc-anode and steel reinforcement, and is much lower than the electric fields usually applied (about 1 Ampere $/ \mathrm{m}^{2}$ ) for electrochemical chloride extraction [11]. Migration is only slightly influenced by the applied electric field at high electric fields (e.g. $5-10$ Volts, about 1 Ampere $/ \mathrm{m}^{2}$ ) and mainly controlled by the current [12]. The influence of the electric field on migration at very low field strength is not well studied.

Therefore, the performance of an EZA embedded into a chloride free embedding TAS binder (shrinkage reduced embedding zinc activating cement - SEZAC) was studied and evaluated under controlled laboratory conditions. The influence of the galvanic field on the ion distribution, especially on the chloride distribution in the concrete overlay and the embedding binder could be evaluated and visualized by LIBS - laser induced breakdown spectroscopy. Results are reported in this paper; evaluations by REM and EDX are under way and will be reported soon in CCR (Cement and Concrete Research).

\section{Experimental}

\subsection{Galvanic Anode/Mortar Probe}

Table 1: steel reinforced mortar - test plates

\begin{tabular}{|c|c|c|}
\hline $\begin{array}{l}\text { dimensions } \\
\text { steel reinforce- } \\
\text { ment }\end{array}$ & $\begin{array}{l}26 \times 17 \times 6 \mathrm{~cm} \\
\varnothing 10 \mathrm{~mm} \\
\text { spacing: e } 17 \\
\text { connecting steel }\end{array}$ & $\begin{array}{l}4 \text { bars à } 240 \mathrm{~mm} \\
4 \mathrm{~mm} \& 6 \mathrm{~mm}\end{array}$ \\
\hline mortar & $\begin{array}{l}\text { SikaMonotop } \\
412 \mathrm{~N} \\
\text { water } \\
\text { sodium chloride }\end{array}$ & $\begin{array}{l}13,85 \mathrm{~kg} \\
2,0 \mathrm{~kg} \\
0,242 \mathrm{~kg} \\
0,84 \mathrm{wt} . \% \mathrm{Cl} / \mathrm{kg} \\
\text { fresh mortar }\end{array}$ \\
\hline reference cell & ERE 20 & Type: $\mathrm{Mn} / \mathrm{MnO}_{2}$ \\
\hline
\end{tabular}

Note: SikaMonotop $412 \mathrm{~N}$ mortar was chosen as being certified for $\mathrm{CP}$ use. The cement content is rather high $\left(640 \mathrm{~kg} / \mathrm{m}^{3}\right.$ fresh mortar).

Embedding binder for zinc mesh: geopolymer based 2component SEZAC binder admixed with ground marble filler. Mixing ratio component $\mathrm{A}$ (binder), component $\mathrm{B}$ (aqueous high alkali potassium silicate), Filler $(0,2-0,5$ mm ground marble):

\section{A : B : Filler $=100: 50: 104$}

Specific weight of wet binder: $\quad 1,84 \mathrm{~kg} / \mathrm{liter}$

Zinc-mesh: $99 \%$ zinc alloy, mesh size $5 \mathrm{~mm}-7 \mathrm{~mm}$, wire diameter $1,1 \mathrm{~mm} ; 2,7 \mathrm{~kg}$ zinc $/ \mathrm{m}^{2}$ mortar surface, $1,1 \mathrm{~kg}$ zinc-mesh per plate embedded into $0,750 \mathrm{~kg}$ SEZAC binder.
The EZA probes were stored at $99 \%$ rh at RT for 1 week for initial hardening and then stored at $80 \%$ rh for an additional week.

\subsection{Operation of the EZA Galvanic Anode System}

The EZA probes were stored in a climatized compartment at $75 \% \mathrm{rh}$. Current between the steel reinforcement and the zinc anode was measured over a $0,1 \mathrm{Ohm}$ shunt and transformed into voltage with an operational amplifier. Steel potentials were measured with a $20 \mathrm{M} \Omega$ input impedance. Data were recorded by a MODAC data logger. Additionally, steel potentials were measured manually with an $\mathrm{Ag} / \mathrm{AgCl}$ reference cell placed onto the surface of the mortar probe.

\subsection{Laser Induced Breakdown Spectroscopy (LIBS)}

The LIBS technique was used for the investigation of the ion transport processes . LIBS - is a combination of laser ablation and plasma generation by a short (ns) high energy (several $\mathrm{mJ}$ ) laser pulse and the analysis of the emitted radiation by optical spectroscopy. LIBS can capture all elements of the periodic table simultaneously through the underlying measurement principle [13]. An overview of the potential of LIBS for the investigation of building materials can be found in the literature [13-17]. For the investigation in this paper the FiberLIBSlab system from SECOPTA analytics was used (see fig. 1).
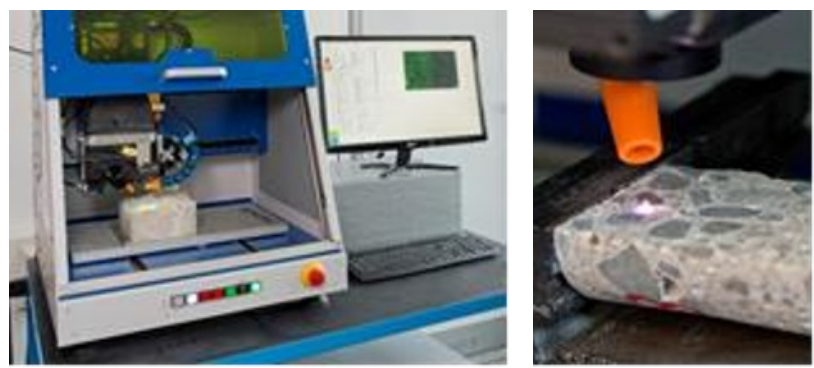

Fig. 1. Overall view of the LIBS laboratory system (left). Detailed view on the sample surface with plasma and nozzle of helium feeder (right).

For the quantitative analysis, a calibration of the system with 15 reference samples based on cement (CEM I) with a concentration range of chloride of 0,05 to $2,5 \mathrm{wt} \%$ was performed. The limit of detection for chlorine in concrete is $0,04 \%$ regarding to the mass of cement. A scanner is used to obtain a two-dimensional element mapping.

All the elements listed in table 2 were recorded simultaneously for each measuring point. The multielement information can be used for exclusion of aggregates, rebars or points belonging to the zinc anode by defining limits for the LIBS-signals in the software. 
Table 2: main parameters of the used LIBS system

\begin{tabular}{|l|l|}
\hline Plasma generation & Detection of radiation \\
\hline NdCr:YAG-laser: & spectrometer: \\
$1064 \mathrm{~nm}, 3 \mathrm{~mJ}, 1.5 \mathrm{~ns}$, & Czerny-Turner \\
$100 \mathrm{~Hz}$ & 1200 lines $/ \mathrm{mm}, 2048$ pixel \\
passive Q-switch & temperature stabilised \\
\hline$\varnothing$ laser spot: & NIR $750 \mathrm{~nm}-950 \mathrm{~nm}$ \\
$80 \mu \mathrm{m}$ & UV $230 \mathrm{~nm}-500 \mathrm{~nm}$ \\
\hline power density: & elements: \\
$40 \mathrm{GW} / \mathrm{cm}^{2}$ & NIR: Ca, O, K, Na, Cl, C, S \\
& UV: Ca, Si, Mg, Al, Fe, Ag, Ti \\
\hline process gas: & \multicolumn{2}{|c|}{ helium } \\
integrated scanner: & $\mathrm{A}_{\max .}=14 \mathrm{~cm} \mathrm{x} 17 \mathrm{~cm}$ \\
\hline
\end{tabular}

The galvanic anode/mortar probes were cut along the broad side for performing the LIBS measurements on the cross-section as shown in fig. 2:

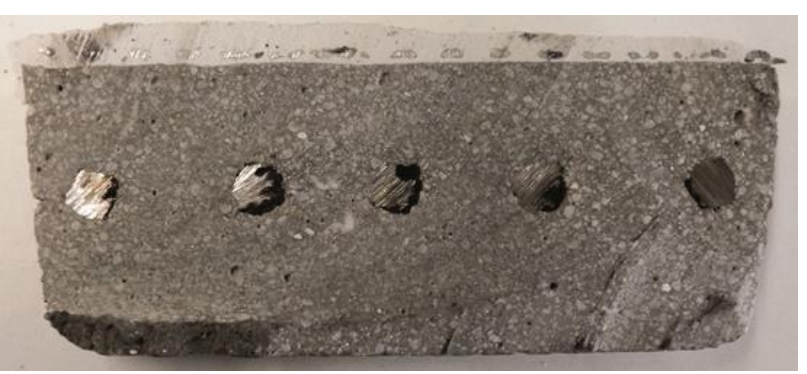

Fig. 2. Galvanic anode/mortar probe cut broadside for LIBS measurements

On the sample an area of about $85 \mathrm{~mm}$ by $65 \mathrm{~mm}$ measurements were taken with a spatial resolution of 0.5 $\mathrm{mm} \times 0,5 \mathrm{~mm}$. As result the element distribution was plotted as multicolor image over the measured area (e.g. figure 4). Three samples were prepared after 5 months, 7 months and 12 months of galvanic operation.

\section{Results}

\subsection{Galvanic Performance}

The galvanic current between the EZA mounted on the mortar probe stored in a climatized chamber $(75 \% \mathrm{rh}, 20$ $-25^{\circ} \mathrm{C}$ ) and the steel reinforcement was monitored. The current flow over one years' time is shown in figure 3 .

The galvanic current stabilized after about 8 months of operation at $7-10 \mathrm{~mA} / \mathrm{m}^{2}$. Galvanic operation resulted in a significant shift of the steel potentials towards positive values (operational data are summarized in table 3 ). $24 \mathrm{~h}$ depolarisation according to EN 12696 after 12 months of operation yielded a value of $138 \mathrm{mV}$.

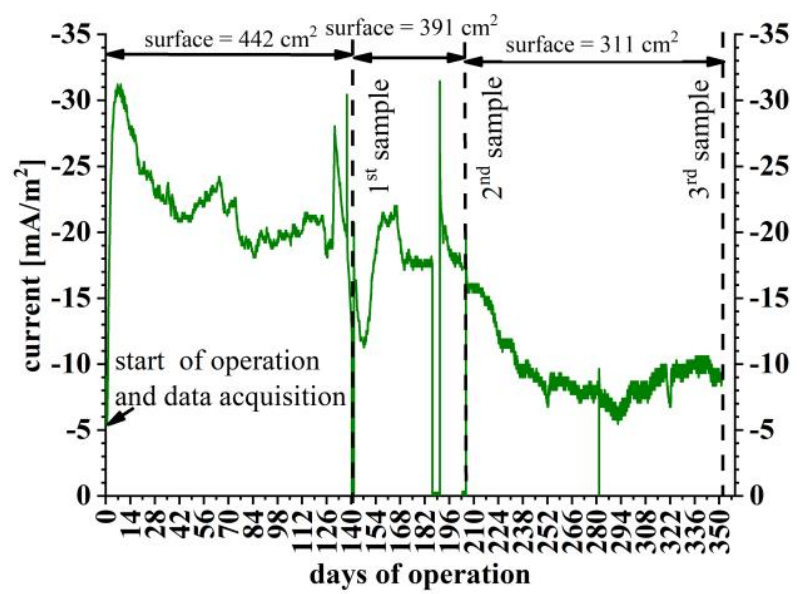

Fig. 3. Galvanic current flow over time at $75 \%$ rh and RT.

Table 3. steel potentials before and during galvanic operation of EZA mounted on the mortar probe during $24 \mathrm{~h}$ depolarisation measurements (off-potentials)

\begin{tabular}{|c|c|c|c|}
\hline $\begin{array}{c}\text { Time of galvanic } \\
\text { operation [month] }\end{array}$ & 0 & 5 & 12 \\
\hline $\begin{array}{c}24 \text { h off-potential } \\
{[\mathrm{mV}]}\end{array}$ & -374 & -246 & -172 \\
\hline $\begin{array}{c}\text { Charge passed [kC] } \\
\text { 0 }\end{array}$ & 261 & 476 \\
\hline
\end{tabular}

After 12 months of operation, no visible corrosion of the zinc anode could be detected (figure 2).

\subsection{LIBS measurements}

LIBS measurements were performed on samples cut after 5, 7 and 12 months of galvanic operation of EZA mounted on the mortar probe.
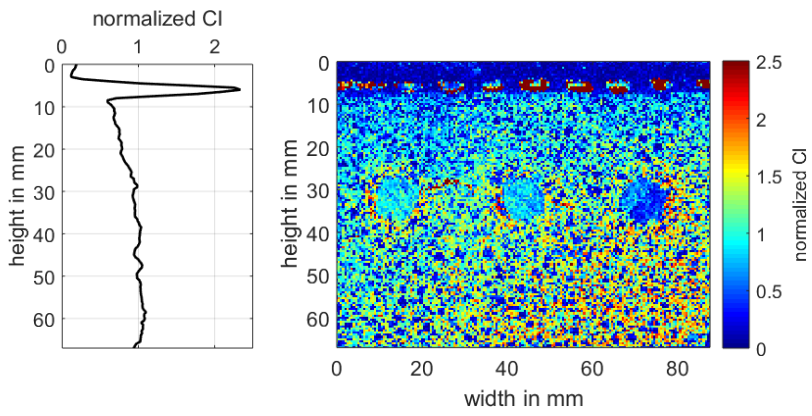

Fig. 4. Color coded chlorine distribution determined by LIBS in the cross section of EZA/mortar probe after 7 months of galvanic operation (right) and depth profile of chlorine (left). The chloride content is normalized to the chloride content of the mortar in areas not exposed to the electric field generated by the galvanic current. 
After 7 months of operation, chloride migration towards the anode was significant, creating a depletion zone between the steel reinforcement (that was not yet visible after 5 month of galvanic operation) and the zinc-anode. The chloride accumulated near the zinc-anode - there was no chloride in the binder material itself detectable (figure 4) and the chloride gradient between steel reinforcement (cathode) and anode increased significantly after 5 months additional galvanic operation (figure 5).

Note: the circular area with an apparent red circle in it (o), between the two rebars on the centre right originates from a cut $\mathrm{Ag} / \mathrm{AgCl}$ reference cell, the red circle is due to the $\mathrm{KCl}$ electrolyte.
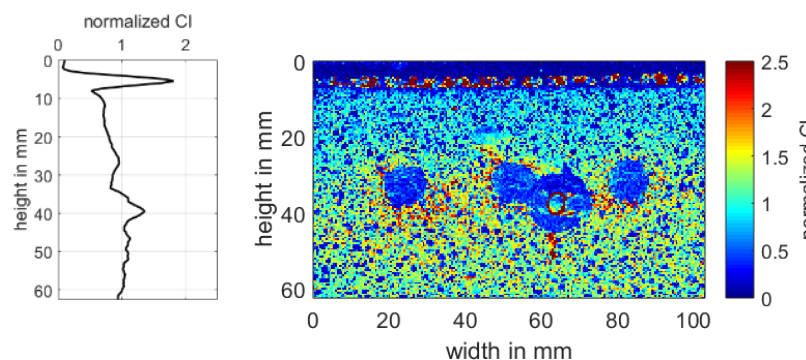

Fig. 5. Color coded chlorine distribution determined by LIBS in the cross section of EZA/mortar probe after 12 months of galvanic operation (right) and depth profile of chlorine (left).

The software of the LIBS allows, as described in chapter 2.3., the exclusion of the areas that contain zinc, iron and aggregate as shown in figure $6 \& 7$ : In the area of $\mathrm{Zn}$ exclusion, chloride concentration was zero - indicating that the chloride was linked to zinc products accumulated in the vicinity of the zinc-anode, such as zinc-hydroxide.

The given quantitative chloride values (Fig. 6) should only be regarded as guide values. As already mentioned, the LIBS system was calibrated with cement-based reference samples (CEM I). A deviation from the material can lead to errors in quantification due to matrix effects (e.g. here the binder).
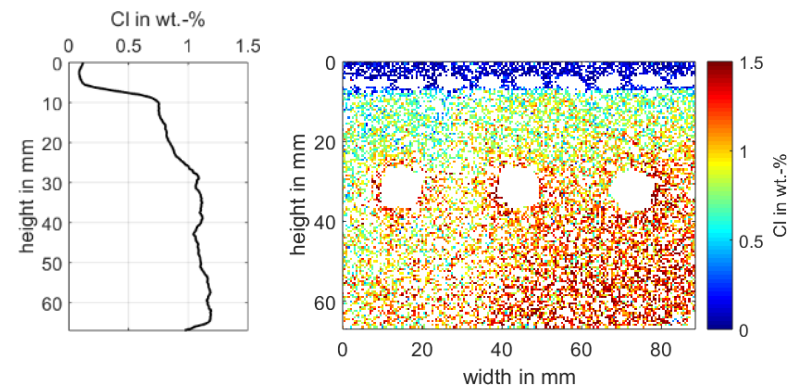

Fig. 6. Chloride distribution determined by LIBS in the cross section EZA/mortar probe after 7 months of galvanic operation: Zn, Fe \& aggregate excluded/deducted (white).

This data supports the hypothesis that chloride forms with the zinc-hydroxide a zinc-hydroxy-chloride, e.g. zinc chloride hydroxide monohydrate (Simonkolleite). The nature of the mineral phases formed near the zinc anode is currently being investigated by REM and EDX and will be published soon.
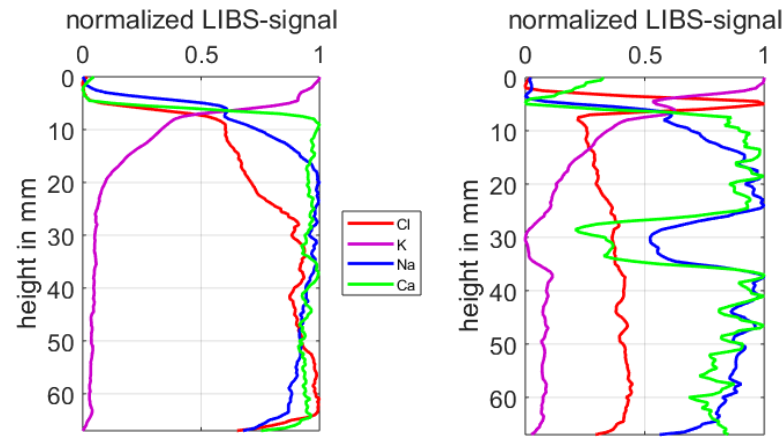

Fig. 7. Ion distribution determined by LIBS in the cross section EZA/mortar probe after 7 months of galvanic operation: $\mathrm{Zn}, \mathrm{Fe}$ $\&$ aggregate excluded/deducted (left graph) in comparison with the ion distribution without exclusion (right graph).

The distribution of chloride, potassium, sodium and calcium under the exclusion of aggregate, iron and zinc in the cross-section of the EZA-mortar probe is shown in figure 7: The chloride depletion zone is clearly visible (left graph in fig. 7). Sodium and potassium migrate towards the cathode - the binder is rich in potassium, free in sodium and nearly calcium-free - calcium is detected only in the mortar phase and in the aggregates in the binder phase (figure 7 , ion distribution without exclusion). The absence of calcium in the binder is essential for the functioning of the SEZAC binder as zinc-activating cement.

\section{Summary and outlook}

The evaluation of elemental distribution in the concrete/binder matrix by LIBS allows the investigation and graphical representation of the changes in the ion distribution caused by the applied electric field.

The results show that there is a significant accumulation of chloride in the vicinity of the zincanode directly linked to the local presence of zinc compounds resulting from the anodic reaction of zinc. There is no chloride in the binder surrounding the zincanode indicating that the chloride may be bound by the anodic products of the zinc anode.

A significant chloride gradient showing decreasing chloride concentration from the steel reinforcement towards the zinc anode indicates chloride extraction into binder/zinc-anode placed on the mortar surface. The results indicate that significant chloride extraction may occur on a time scale of a magnitude larger than the time period of observation (12 month).

However, one has to take into account the high cement content of the mortar $\left(700 \mathrm{~kg} / \mathrm{m}^{3}\right)$ that will chemically absorb significant amounts of chloride and therefore significantly impede chloride migration. Therefore, chloride migration during galvanic corrosion protection in probes with a cement content of the mortar more common to field situations - max. $300 \mathrm{~kg} / \mathrm{m}^{3}$ should be studied.

The results indicate that the chloride is chemically bound in the vicinity of the zinc anode therefore 
impeding back diffusion of chloride into the mortar/concrete matrix. The identification of the mineral phases and their chemical composition of the zinccompounds in which chloride is bound are important and are underway. The results will be reported soon.

\section{References}

1. J.L. Kepler, D. Darwin and J.R. Locke, Evaluation of Corrosion Protection Methods for Reinforced Concrete Highway Structures, Structural Engineering and Engineering Materials SM Report No. 58, University of Kansas Center for Research Inc., Lawrence, Kansas, May 2000

2. Y. P. Virmany, G.G. Clemena, Corrosion ProtectionConcrete Bridges, Report No. FHWA-RD-98-088, Federal Highway Administration, Washington, D.C., 1998

3. R.J. Kessler, R.G. Powers, and I.R. Lasa, Un update on the long-term use of cathodic protection of marine structures, Corrosion 2002, paper 02254, NACE International

4. S. Szabo, I. Bakos, Cathodic Protection with Sacrificial Anodes, Corrosion Reviews 24: 2006, pp. $231-280$

5. S.J. Bullard, S. Cramer and B.Covino, Final ReportEffectiveness of Cathodic Protection, SPR 345. Report No. FHWA-OR-RD-09-18, National Energy Technology Laboratory, Oregon, 2009

6. W. Schwarz, A. Pichlhöfer, A. van den Hondel and $\mathrm{H}$. Esteves, Maintenance and repair of steel reinforced concrete structures by galvanic corrosion protection - field experiences over 10 years, ICCRRR 2018 Cape Town, South Africa, November 19-21, 2018, in MATEC Web of Conferences 199, 05005 (2018)

7. W. Schwarz, F. Müllner, A.J. van den Hondel, Maintenance and repair of steel reinforced concrete structures by simultaneous galvanic corrosion protection and chloride extraction, fib Symposium 2016, Cape Town, South Africa 21-23 November 2016

8. A. Delagrave, J. Marchaud, and E. Samson, Prediction of Diffusion Coefficients in Cement-Based Materials on The Basis of Migration Experiments, Cement and Concrete Research, Vol. 26, No. 12, pp. 1831-1842, 1996

9. C. Andrade, Calculation of chloride diffusion coefficients in concrete from ionic migration measurements, Cement and Concrete Research, Volume 23, Issue 3, May 1993, Pages 724-742

10. L. Tang, H. E. Sørensen, Precision of the Nordic test methods for measuring the chloride diffusion/migration coefficients of concrete, Materials and Structures, Vol. 34, October 2001, pp 479-485

11. B. Elsener, U. Angst, Mechanism of electrochemical chloride removal, Corrosion Science, Volume 49, Issue 12, December 2007, 4504-4522
12. E. Samson, J. Marchand, K.A. Snyder, Calculation of ionic diffusion coefficients on the basis of migration test results, Materials and Structures, Vol 36, April 2003, pp $156-165$

13. Cremers, D.; Radzemski, L., 2006: Handbook of Laser-induced Breakdown Spectroscopy, John Wiley $\&$ Sons Ltd (2006).

14. G. Wilsch, F. Weritz, D. Schaurich, H. Wiggenhauser, Determination of chloride content in concrete structures with laser-induced breakdown spectroscopy, Construction and Building Materials $\begin{array}{llllll}19 & (10) & \text { (2005) } & 724 & - & 730 .\end{array}$ doi:10.1016/j.conbuildmat.2005.06.001.

15. G. Wilsch, D. Schaurich, H. Wiggenhauser, Imaging laser analysis of building materials - practical examples, AIP Conference Proceedings 1335 (1) (2011) 1315 - 1322. doi:10.1063/1.3592085.

16. G. Wilsch, T. Eichler, S. Millar and D. Schaurich, Laser Induced Breakdown Spectroscopy (LIBS) alternative to wet chemistry and micro-XRF, CRC Press 2014 (2014) 611 - 615. doi:10.1201/b17394-94

17. S. Millar, C. Gottlieb, T. Guenther, N. Sankat, G. Wilsch, S. Kruschwitz, Chlorine deter-mination in cement-bound materials with Laser-induced Breakdown Spectroscopy (LIBS) - A review and validation, Spectrochimica Acta Part B: Atomic Spectroscopy, Volume 147, September 2018, p. 1-8 